\title{
Performance of Aerobic Microbial Granules in Organic Carbon Removal as a Method in the Treatment of Biodegradable Wastewater
}

\author{
Nanik Indah Setianingsih ${ }^{1,2 *}$, Hadiyanto ${ }^{1}$, Sudarno ${ }^{1}$, Rustiana Yuliasni ${ }^{2}$ \\ ${ }^{1}$ Master Program of Environmental Science, School of Postgraduate Studies, Diponegoro University, Indonesia \\ ${ }^{2}$ Centre of Industrial Pollution Prevention Technology, Ministry of Industry, Indonesia
}

\begin{abstract}
Conventional biological wastewater treatment is effective in removing organic carbon but has weaknesses in need large area, long hydraulic retention time, produce excess sludge in activated sludge system and need post treatment for removing nutrient in the anaerobic system. Aerobic microbial granules is a biological method in wastewater treatment that potential to overcome the lack of conventional biological treatment. Aerobic granules were developed in SBR made of glass with an effective volume of $10 \mathrm{~L}$. Acetate was used as a source of carbon with COD concentration 900-1200 mg/L. SBR was run in anaerobic and aerobic phase with a hydraulic retention time of 8,3 hours and an exchange ratio of $60 \%$. Granules begin to be formed after 14 days operational period with SVI30 to SVI5 ratio reach on 0,97 and settling velocity $13,8 \mathrm{~cm} /$ minute. High performance in degrading organic carbon is shown by aerobic microbial granules system with removal efficiency reaches on $94-97 \%$.
\end{abstract}

Keywords: aerobic granules; biodegradable wastewater; organic carbon.

\section{Introduction}

Biological treatment is a method of wastewater treatment claimed more economical and environmentally friendly than physical or chemical wastewater treatment. In Indonesia, biological treatment still widely used for biodegradable wastewater treatment both anaerobic and aerobically. Conventional biological wastewater treatment is effective methods in removing organic carbon but in other hands still have weaknesses such as need a large area, long hydraulic retention time, produce excess sludge in activated sludge system [1] and need post treatment for removing nutrient in the anaerobic system. To overcome the shortcomings, other biological treatment needs to be tried. Aerobic microbial granule is a biological treatment that less studied and applied in Indonesia hopefully become as an alternative way to overcome the lack of conventional biological treatment.

Compared with conventional biological treatment, aerobic microbial granules have shorter hydraulic retention time, higher pollutant loading strength and better in dealing with shock loading [2-4]. In laboratory scale, aerobic microbial granules have been studied to treat biodegradable pollutant $[5,6]$, nutrient $[7,8]$ even toxic component [9]. Besides the ability to remove pollutants, aerobic microbial granules can be inactivated and be stored for some period of time without aeration, then later can be re-activated to be used as seed [10].
Moreover, the higher of settling velocity of aerobic microbial granule compared to activated sludge makes it possible to be operated in a more compact reactor design.

Aerobic granules have been developed and successfully treated brewery wastewater [11], wine industry wastewater [12] even phenolic wastewater [13]. These advantages hopefully make aerobic microbial granules could be low-cost alternative for full scale application of biological wastewater treatment technology. This research aims to develop aerobic microbial granules with a compact structure for removing organic carbon as an alternative in the biological treatment of biodegradable wastewater.

\section{Methods}

\subsection{Materials}

Sludge from the bakery industry activated sludge system was used as seed. Acetate was used as a source of organic carbon with COD concentration 900-1200 mg/L. Macronutrients were added in the ratio of COD:N: $\mathrm{P}=$ 100:5:1. Micronutrients such as buffer phosphate, $\mathrm{FeCl} 3$ and $\mathrm{Mg}(\mathrm{SO} 4)$ were added.Sequencing Batch Reactor (SBR) made of glass with dimension $\mathrm{h}=100 \mathrm{~cm}, \mathrm{D}=$ $14,14 \mathrm{~cm}, \mathrm{~V}=10 \mathrm{~L}$ was used. An aeration unit with

\footnotetext{
$\overline{{ }^{*} \text { Corresponding author: amifaira497@gmail.com }}$
} 
diffusers was inserted inside the SBR. SBR was aerated continuously until the reactor was ready to be used.

\subsection{Procedure}

Sludge seed $4 \mathrm{~L}$ volume was inserted in SBR, then $6 \mathrm{~L}$ acetate with COD concentration 900-1000 mg/L was added. SBR was operated in the two cycles per day, each cycle running in 310 minutes that consisted of feeding time $2,5 \mathrm{~min}$, anaerobic phase $90 \mathrm{~min}$, aerobic phase 210 min, settling time $5 \mathrm{~min}$ and $2,5 \mathrm{~min}$ for draw time of effluent. The airflow rate was 3-10 L/minute, dissolved oxygen in the anaerobic phase was $0-0,6 \mathrm{mg} / \mathrm{L}$ whereas in aerobic condition was $2-4 \mathrm{mg} / \mathrm{L}$. In idle phase, the reactor was operated with airflow velocity $3 \mathrm{~L} /$ minute without feeding. Hydraulic retention time (HRT) was 8,3 hour and effluent was discharged with a volumetric exchange ratio of $60 \%$.

Observation parameters were sludge volume index (SVI), settling velocity, Suspended Solid (SS) and Chemical Oxygen Demand (COD) that measured according to ASTM of water and wastewater [14]. The dimension of the granule was measured by determining particle size distribution that analyzed using the sieving method stated by Laguna et al [15]. The screening was performed using stainless steel sieves having diameter 8 inches with mesh openings of $2 ; 1.4 ; 1 ; 0.7$ and $0.3 \mathrm{~mm}$. The sample with a diameter less than $0.3 \mathrm{~mm}$ was defined as floc and the other samples with a diameter more than $0.3 \mathrm{~mm}$ were defined as granules.

\section{Result and discussion}

\subsection{Particle Size Distribution}

In the experiments visually observed that granules begin to be formed on day 14 after reactor operation (Fig. 1). Particle size distribution analysis conducted for sample on day 1 (floc), day 14 (first granule) and day 34 (mature granule). The result of particle size distribution analysis is presented in Fig. 2.

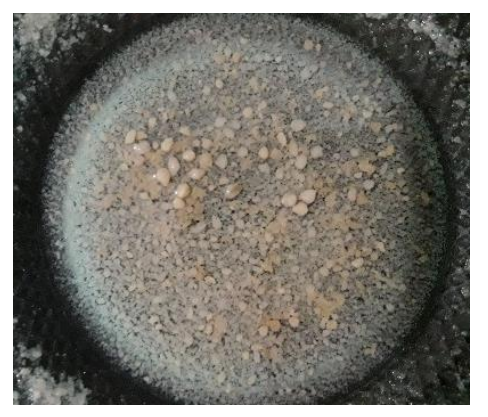

Fig. 1. Visual of aerobic granules on day 14

We can evaluate in Fig. 2 that, in day 1 all the sample is categorized as floc with diameter less than $0.3 \mathrm{~mm}$, and after 14 days operation the granules begin formed, marked by increasing of diameter biomass. In day 14 percentage of the granule is $60,6 \%$ and an increase in day 34 reach on $76,74 \%$. The highest percentage in day 14 is granules with particle size $1 \mathrm{~mm}<\mathrm{d}<1,4 \mathrm{~mm}$ in the amount of $19,44 \%$, whereas in day 34 is granules with particle size $0,3 \mathrm{~mm}<\mathrm{d}<0,7 \mathrm{~mm}$ reached on $34,91 \%$. Kuan Y. S et al. [10] revealed that smaller size granules tend to be denser than larger size granules, so during the granulation process in the experiment there is increasing of granule density.

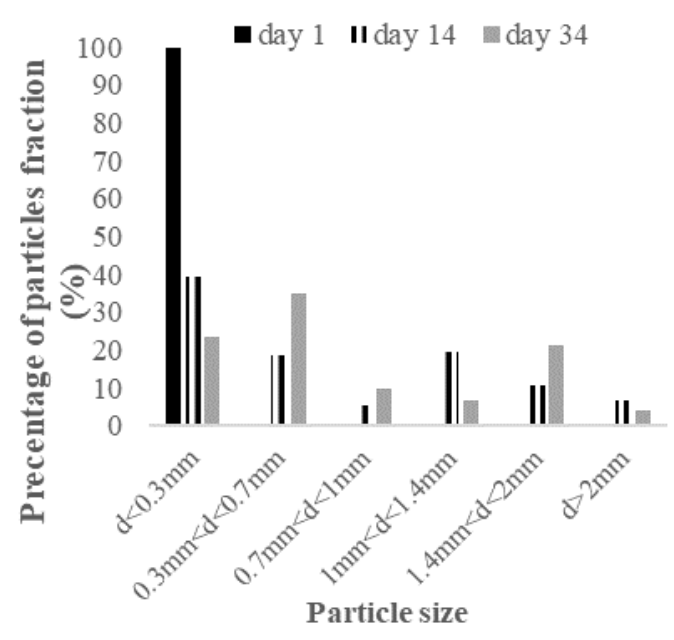

Fig. 2. Particle size distribution analysis of aerobic granules

\subsection{Sludge Volume Index dan Settling Velocity}

The characteristic of sludge volume index (SVI) parameter during the operation process reactor is depicted in Fig. 3.

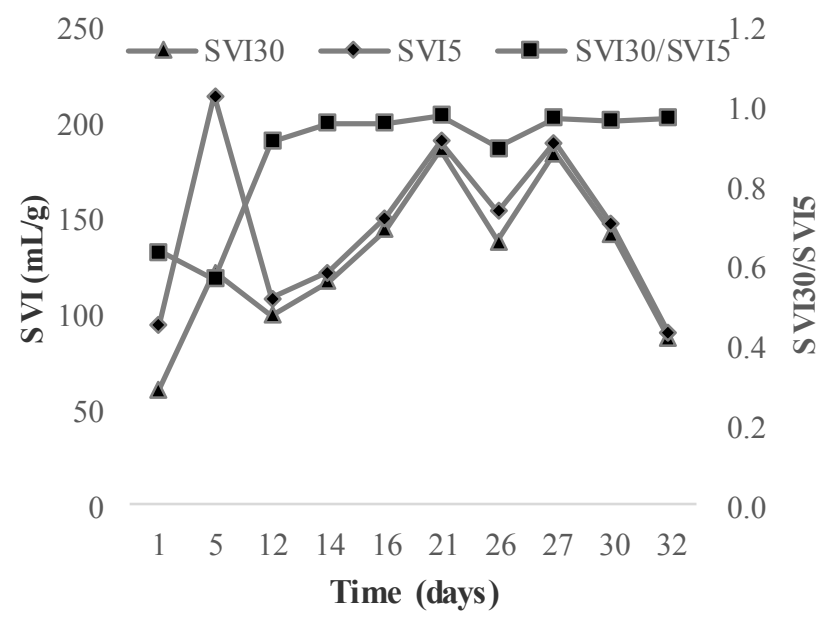

Fig. 3. Sludge volume index (SVI) analysis of aerobic granules

The sludge volume index (SVI) parameter is used to describe the sedimentation characteristic of the sludge and granule that formed during the operational period. In this study, SVI was observed in the 5 and 30 minutes, then determined the ratio between SVI30 to SVI5 to observe the extent of thickening in the process of granules sedimentation. According to A.van Haandel [16], the thickening of the granules after 5 minutes first was limited, hence the ratio of SVI30 to SVI5 become an indication of the presence of aerobic microbial granules. 
If the value of the ratio SVI30 to SVI5 is closer to 1, the granule is getting more compact as the difference of settling rate in the 5 minutes first and 30 minutes is getting smaller.

The result of SVI parameter analysis showed that the granules begin to be formed on day 14 with the SVI ratio value is 0.97 , and tend to be stable until day 32 . The value of SVI5 has the same trend as SVI30. The initial SVI5 value is $94.10 \mathrm{~mL} / \mathrm{g}$ and fluctuate during the operational period until day 27 , and tend to decrease until the last day with SVI5 value is $89.51 \mathrm{~mL} / \mathrm{g}$, whereas the initial SVI30 value is $59.88 \mathrm{~mL} / \mathrm{g}$ and also fluctuate during reactor operation until day 27 and tend to decrease until day 32 with SVI30 value is $86.96 \mathrm{~mL} / \mathrm{g}$.

As revealed in Fig. 3 the trend ratio of SVI30 to SVI5 is increasing, and starts tend to stable on day 14. This indicates that on day 14 the extent of thickening in the process of granules sedimentation is limited, this is also in line by visual observation where granules begin to be formed on day 14. The initial value of ratio SVI30 to SVI5 is 0.64 then increases and tends to be stable until day 32 with value of ratio SVI30 to SVI5 is 0.97 and this result is higher compared to the SVI30 ratio of SVI5 conducted by Moghaddam, S.S. \& Moghaddam, M.R.A [17], where the highest value of ratio SVI30 to SVI5 at the granule formation stage with acetate feed is 0.81 .

Another parameter for evaluation in granule formation is settling velocity. Analysis of the relationship between settling velocity and the ratio of SVI30 to SVI5 is presented in Fig. 4.

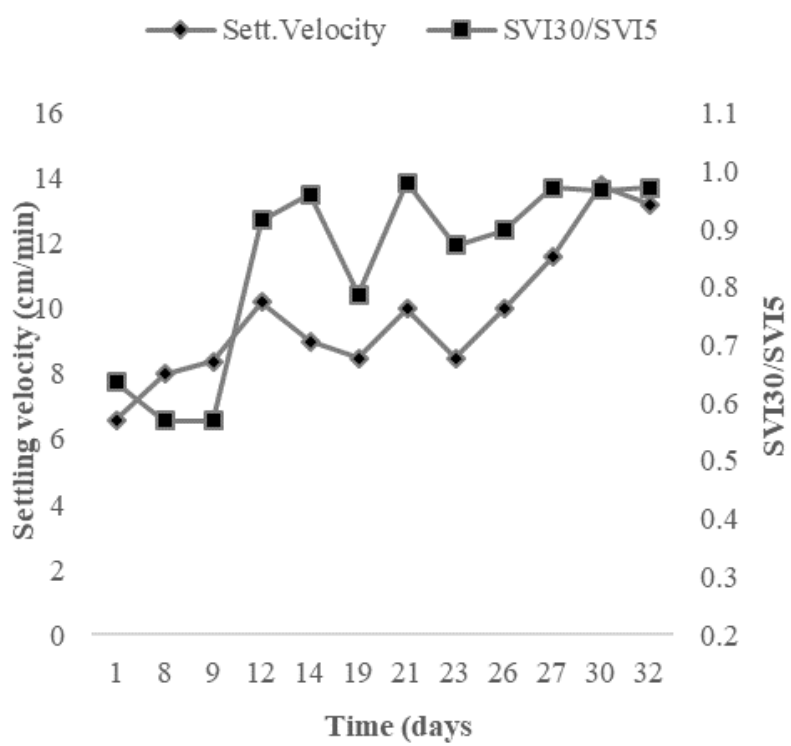

Fig. 4. Settling velocity analysis of aerobic granules

In Fig. 4, can be evaluated the initial settling rate of sludge is $6.6 \mathrm{~cm} /$ minute and increases although it fluctuates until day 23 and tends to increases until day 32 reaches on $13.8 \mathrm{~cm} /$ minute. This result shows that there is a change on biomass in the granulation process from floc to be granule which has higher settling velocity. Start from day 14 , the trend of settling velocity is likely to be the same as the trend of ratio SVI30 to SVI5.

\subsection{Performance of removal organic carbon}

In this research acetate was used as source of organic carbon in development aerobic microbial granules. COD removal efficiency during operational period is shown in Fig. 5.

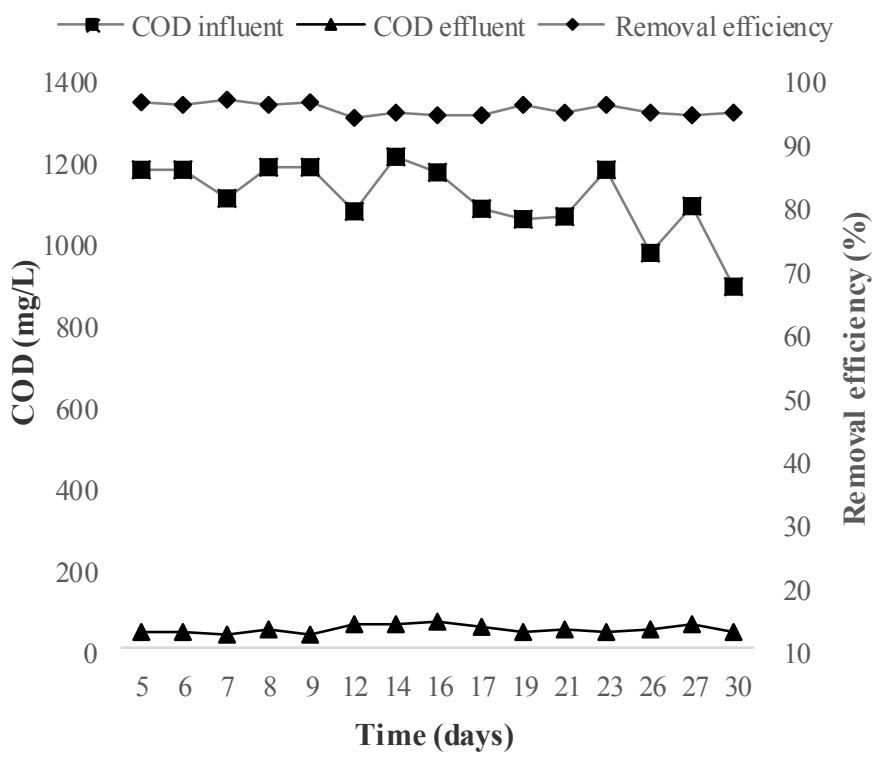

Fig. 5. COD removal efficiency during operational time

As depicted in Fig. 5, almost organic carbon completely degraded with COD influent concentration $900-1200 \mathrm{mg} / \mathrm{L}$ and COD removal efficiency reaches on 94-97\% during operation time. This result is almost the same as the result of Moghaddam, S.S. \& Moghaddam, M.R.A [17] that removal efficiency of COD in granulation period with acetate as a source of carbon was $90-97 \%$ and Garucci et al. [1] mentioned higher result with acetate removal efficiency reached on $99 \%$. Those results prove that organic carbon could be completely degraded by aerobic granules.

\section{Conclusion}

Aerobic microbial granules are successfully developed with acetate as a source of carbon begin in 14 days operation time reactor. The granules density increases during the operational period and in line with the increasing of settling velocity and SVI30 to the SVI5 ratio of the granules. High performance in degrading organic carbon is shown by aerobic microbial granules system with removal efficiency reaches on $94-97 \%$.

\section{Acknowledgment}

The authors would like to express their gratitude to the Centre of Industrial Pollution Prevention Technology for funding support, and all team for supporting in the research project. 


\section{References}

1. A. Garucci, M. Stefano D.G. Giorgia, M. Piredda, Acetate-Fed Aerobic Granular Sludge for the Degradation of 4-Chlorophenol, Journal of Hazardous Materials 166, 483-490 (2009)

2. S.S. Adav, D.J. Lee, K.Y. Show, J.H. Tay, Aerobic Granular Sludge: Recent Advances, Biotechnology Advances 26, 411-423 (2008)

3. X.H. Wang, H.M. Zhang, F.L. Yang, Y.F. Wang, M.M. Gao, Long-term Storage and Subsequent Reactivation of Aerobic Granules, Bioresource Technology 99, 8304-8309 (2008)

4. A. Lopez, J. Dosta, J. Mata-Alvarez, Start-Up of an Aerobic Granular Sequencing Batch Reactor for the Treatment of Winery Wastewater, Water Science and Technology 60, 1049-1054 (2009)

5. B.Y.P. Moy, J.H. Tay, S.K. Toh, Y. Liu, S.T.L Tay, High Organic Loading Influences the Physical Characteristics of Aerobic Sludge Granules, Letters in Applied Microbiology 34, 407-412 (2002)

6. J.H.W. Tay, S.T.L. Tay, Y. Liu, K.Y. Show, V. Ivanov, Biogranulation Technologies for Wastewater Treatment, New York: Elsevier (2006)

7. Y.M. Lin, Y. Liu, J.H Tay, Development and Characteristics of Phosphorous-Accumulating Granules in Sequencing Batch Reactor, Applied Microbiology and Biotechnology 62, 430-435 (2003)

8. M. Sarvajith, G.K.K. Reddy, Y.V. Nancharaiah, Textile Dye Biodecolourization and Ammonium Removal Over Nitrite in Aerobic Granular Sludge Sequencing Batch Reactors, Journal of Hazardous Materials (2017)

9. Z.X. Xiang, L.L. Zhang, J.M Chen, Aniline Removal by Aerobic Granules and High Efficiency Aniline-Degrading Bacteria, Huanjing Kexue 30, 3336-3341 (2009)

10. Y.S. Kuan, J.L. Duu, H.T. Joo, Aerobic Granulation: Advances and Challenges, Appl Biochem Biotechnol 167, 1622-1640 (2012)

11. S.G. Wang, X.W. Liu, W.X. Gong, B.Y. Gao, D.H. Zhan, H.Q. Yu, Aerobic Granulation with Brewery Wastewater in a Sequencing Batch Reactor, Bioresource Technology 98, 2142-2147 (2007)

12. A. Lopez, J. Dosta,M. Alvarez, Start-Up of an Aerobic Granular Sequencing Batch Reactor for the Treatment of Winery Wastewater, Water Science and Technology 60, 1049-1054 (2009)

13. K.L., Ho, Y.Y. Chen, N.B. Li, D.J. Lee, Degrading High-Strength Phenol Using Aerobic Granular Sludge, Applied Microbiology and Biotechnology, 85, 2009-2015 (2010)

14. APHA, AWWA, WPCF, Standard Methods for the Examination of Water and Wastewater (22th ed.), American Public Health Association, Washington, DC, USA (2012)
15. A. Laguna, A. Ouattara, R.O. Gonzalez, O. Baron, G. Fama, R. El Mamouni, S. Guiot, et al, A Simple And Low Cost Technique for Determining the Granulometry of Upflow Anaerobic Sludge Blanket Reactor Sludge, Water Sci. Technol. 40, 1-8 (1999)

16. A.V. Haandel, J.V.D. Lubbe, Handbook Biological Waste Water Treatment-Design and Optimisation of Activated Sludge System, Quist Publishing, Leidschendam, The Netherlands (2007)

17. S.S. Moghaddam, M.R.A. Moghaddam, Aerobic Granular Sludge for Dye Biodegradation in a Sequencing Batch Reactor with Anaerobic/Aerobic Cycles, Clean Soil Air Water 44(4), 438-443 (2016) 